BMJ Open

Sport \&

Exercise

Medicine

\title{
Systematic review of physical activity and exercise interventions to improve health, fitness and well-being of children and young people who use wheelchairs
}

Thomas D O'Brien, ${ }^{1}$ Jane Noyes, ${ }^{2}$ Llinos Haf Spencer, ${ }^{3}$ Hans-Peter Kubis, ${ }^{1}$ Richard P Hastings, ${ }^{4}$ Rhiannon Whitaker ${ }^{5}$

To cite: O'Brien TD, Noyes J, Spencer LH, et al. Systematic review of physical activity and exercise interventions to improve health, fitness and well-being of children and young people who use wheelchairs. BMJ Open Sport Exerc Med 2016;2:e000109. doi:10.1136/bmjsem-2016000109

- Prepublication history and additional material is available. To view please visit the journal (http://dx.doi.org/ 10.1136/bmjsem-2016000109).

Received 4 January 2016 Revised 15 September 2016 Accepted 19 September 2016

CrossMark

For numbered affiliations see end of article.

Correspondence to Dr Thomas D O'Brien; t.d.obrien@ljmu.ac.uk

\section{ABSTRACT}

Aim: To perform a systematic review establishing the current evidence base for physical activity and exercise interventions that promote health, fitness and wellbeing, rather than specific functional improvements, for children who use wheelchairs.

Design: A systematic review using a mixed methods design.

Data sources: A wide range of databases, including Web of Science, PubMed, BMJ Best Practice, NHS EED, CINAHL, AMED, NICAN, PsychINFO, were searched for quantitative, qualitative and health economics evidence.

Eligibility: participants: children/young people aged $>25$ years who use a wheelchair, or parents and therapists/carers. Intervention: home-based or community-based physical activity to improve health, fitness and well-being.

Results: Thirty quantitative studies that measured indicators of health, fitness and well-being and one qualitative study were included. Studies were very heterogeneous preventing a meta-analysis, and the risk of bias was generally high. Most studies focused on children with cerebral palsy and used an outcome measure of walking or standing, indicating that they were generally designed for children with already good motor function and mobility. Improvements in health, fitness and well-being were found across the range of outcome types. There were no reports of negative changes. No economics evidence was found.

Conclusions: It was found that children who use wheelchairs can participate in physical activity interventions safely. The paucity of robust studies evaluating interventions to improve health and fitness is concerning. This hinders adequate policymaking and guidance for practitioners, and requires urgent attention. However, the evidence that does exist suggests that children who use wheelchairs are able to experience the positive benefits associated with appropriately designed exercise.

Trial registration number: CRD42013003939.
What is already known?

- Physical activity is essential for health and well-being, but for children who use wheelchairs participation rates are low.

- Health policy and guidance on physical activity and exercise for disabled children is lacking.

\section{What are the new findings?}

- No reports of adverse outcomes were found, indicating that children who use wheelchairs can participate in exercise safely.

- Models of delivery using an initial period of individual or group supervision followed by homebased programmes appear effective and could be sustainable within health and wheelchair service practice.

- Evidence on the effectiveness of health and fitness focused exercise interventions for children who use wheelchairs is weak, yet suggests that these children can experience the usual benefits associated with well-designed interventions.

\section{INTRODUCTION}

Participation in exercise and physical activity is vital to maintain health and fitness, and for children it is essential for emotional and physical development. ${ }^{1}$ However, children with mobility impairments face multiple barriers to participation and their uptake rates are lower than those of typically developing children. $^{2} 3$ Children with mobility impairments also tend to be more frequently overweight or obese, physically weaker and less fit than their typically developing peers. ${ }^{45}$ This predisposes them to long-term health risks, including type-2 diabetes and cardiovascular 
disease, and results in a 'debilitative cycle' of poor fitness, increased disability, and further reduced health and well-being. ${ }^{6}$ The consequence is impaired quality of life and future health prospects for the children, and spiralling demands on families and health and social care services. Given that there are 770000 children and young people under the age of 16 years living in the UK with a disability ( 1 in 20 children $^{7}$ ); this is an important issue that must be tackled.

\section{Rationale}

Government policy and guidance on physical activity is well established for adults and typically developing children. ${ }^{8}$ This is also reflected in professional body position statements, ${ }^{9}$ but there is a lack of guidance on physical activity for children with mobility impairments. In the $\mathrm{UK}$, in response to the NICE guidance which omitted disabled children, a specific briefing paper was published and promoted access to play and physical activity for disabled children and young people, ${ }^{10}$ citing physiological benefits as well as enhanced confidence, selfesteem, resilience and social inclusion. While the benefits of increased physical activity levels are clear, it is not apparent what activities actually promote the health and fitness benefits desired for this group of children.

A number of systematic reviews have been undertaken to evaluate a range of interventions to improve physical function in children with mobility impairments. ${ }^{11-16}$ However, the studies reviewed primarily focused on occupational-type or physiotherapy-type therapeutic interventions and outcomes, by which they treated a specific functional impairment such as a joint range of motion or walking function, with a targeted intervention or exercise. Typically such interventions do not provide insights in the wider benefits of exercise and physical activity for health (which we define as the composite of physical, mental and social aspects required for an individual to function, adapt and self-manage) and fitness (which we define as the set attributes required for physical function, that can each be related to specific tests, eg, muscle strength or maximal cardiovascular capacity). By their definitions, health and fitness are interdependent. Consequently, there is a gap in our knowledge relating to (1) intervention effectiveness for health and fitness outcomes, (2) what are the most suitable primary outcomes to assess health and fitness, (3) engagement and long-term adherence, (4) psychological preparation/intervention to promote readiness and motivation to exercise in this group of children, (5) a lack of focus on the most physically disabled children (which for the purposes of this review, we define as those who use wheelchairs all or some of the time) and (6) evaluation of health economics (a further discussion of these points is presented in the protocol of this review $\left.{ }^{17}\right)$. We are not aware of any published systematic reviews of physical activity interventions with the aim of improving health and fitness of children and young people who use a wheelchair.

\section{Objectives}

The purpose of this systematic review was to establish the current evidence base for exercise or physical activity interventions to improve the health and fitness of children and young people who use wheelchairs. We specified the following objectives:

1. To determine the effectiveness and cost-effectiveness of physical activity interventions for children and young people who use a wheelchair within a home and community setting.

2. To describe programme theories/concepts or models and identify appropriate outcome measures in current interventions.

3. To explore the views and experiences of children, young people and their parents, and key stakeholders about physical activity interventions for wheelchair users.

\section{METHODS \\ Design}

We set out to undertake a mixed methods systematic review of quantitative, qualitative and health economics evidence to identify and evaluate effectiveness of physical activity interventions. However, we did not find any economic evidence that met our inclusion criteria. The search strategies and type of evidence to be included in this stream is described in the protocol ${ }^{17}$ (PROSPERO registration: CRD42013003939), but it will not be described further in this review. The review broadly followed design, methods and processes of the Cochrane Effective Practice and Organisation of Care Group (EPOC), ${ }^{18}$ for the synthesis of effect evidence, and Reporting guidance set out in Preferred Reporting Items for Systematic Reviews and Meta-Analyses (PRISMA). ${ }^{19}$

\section{Inclusion criteria}

Population

Our primary objective was to review studies with children and young people who use wheelchairs. Wheelchair use was broadly defined as requiring the use of a wheelchair all or some of the time, even if only for long distances. However, initial pilot searches found that many studies include physically disabled children who do not use wheelchairs along with those who do, or that wheelchair use is not reported for groups that would be expected to use wheelchairs, based on functional classification or medical condition. Consequently, in addition to the studies that reported their samples included 'wheelchair users', studies with probable but 'undefined wheelchair use', as judged by our multidisciplinary team, were also included. These separate groups of studies are handled independently in reporting and synthesis.

Children and young people aged $<25$ years (this upper age limit was chosen to ensure that data from young people under 18 years were not lost, if they were part of a sample, including young adults). 
Types of intervention

Any intervention that included physical activity or exercise at home or in the community. Physical activity and exercise were defined as being general or structured movement of the body that would increase energy expenditure.

To allow a more detailed examination of effectiveness of specific types of exercise or physical activity, interventions were grouped according into activity mode (table 1). Interventions aiming to improve specific disabilities or impairments with targeted programmes (such as physiotherapy or occupational therapy) were excluded.

\section{Types of outcome measures}

Any evidence related to the effectiveness or costeffectiveness of an intervention was considered. To evaluate an intervention's potential to improve specific components of health, fitness and well-being, quantitative data were categorised according to the outcome type. All outcome measures reported in the included studies could be defined as being in one of the following categories. These categories align with those described for assessment in our main project study protocol, ${ }^{20}$ and were used to organise the data only and not as inclusion criteria.

1. Exercise capacity/fitness

2. Metabolism

3. Body composition/weight

4. Quality of life

5. Respiratory function

6. Physical function
A. Gross motor function
B. Mobility
C. Strength

7. Physical activity levels, including self-reported, and attitudes to physical activity
Several of the included studies evaluated walking capacity in tests ranging from 6 to $10 \mathrm{~min}$. These studies were inconsistent in their classification of this outcome as either exercise capacity (outcome type 1) or tests of ambulation and mobility (outcome type 6b). For clarity and consistency in the present systematic review, we classified these to be exercise capacity. Walking tests of $<1 \mathrm{~min}$ or over short distances were classified as mobility.

In most cases, a single study provided data of several outcome types.

\section{Types of studies}

Preliminary pilot searches of existing literature, found few randomised controlled trials (RCTs) of exercise or physical activity interventions for children and young people who use wheelchairs. Therefore, we decided to include all relevant study designs (eg, RCT, non-RCT, controlled before-after, survey, qualitative) to draw from as wide an evidence base as appropriate. Consequently, in some studies, there was no comparison or control group included, and in others the control group consisted of usual care. In cases where the comparison was between two different targeted interventions, these were treated as separate treatments in the same study.

Only publications in English, Welsh or German language were included, reflecting translation capacity within the study team. Grey literature, including contemporary local government/agency, charity reports and intervention programme evaluations which have not been subject to peer review, were also included to limit publication bias and ensure that all relevant literature may be located. Grey literature was screened against criteria of Completeness, Accuracy, Relevance and Timeliness (CART) to determine inclusion or exclusion.

Table 1 Physical activity modes and definitions used for grouping and analysis in this review

\begin{tabular}{|c|c|}
\hline Exercise mode & Further definition for this review \\
\hline Walking & Including treadmill \\
\hline Cycling & Either outdoor or stationary, and peddle or hand/crack \\
\hline Progressive resistance training (PRT) & $\begin{array}{l}\text { Lifting of an external resistance, performed across multiple sets }(3-5) \text { of a low number } \\
\text { of repetitions }(<20)\end{array}$ \\
\hline $\begin{array}{l}\text { Functional/closed kinetic chain } \\
\text { exercises }\end{array}$ & $\begin{array}{l}\text { Lifting, controlling and moving one's own body weight, during movement's replicating } \\
\text { real-life movements, eg, stepping forwards or up on a step, excluding walking only }\end{array}$ \\
\hline $\begin{array}{l}\text { PRT using functional/closed kinetic } \\
\text { chain exercises }\end{array}$ & $\begin{array}{l}\text { Functional exercises, with the addition of external weight; either held in hands or as } \\
\text { weighted vest }\end{array}$ \\
\hline Sport/games-based & Including group or individual game or play based activities \\
\hline Spirometry exercise & Externally resisted inspiratory muscle training \\
\hline Nintendo Wii & Using 'off-the-shelf' games \\
\hline Motivation & $\begin{array}{l}\text { Any study providing psychological or emotional feedback, or music to enhance } \\
\text { motivation during a physical activity }\end{array}$ \\
\hline Education & Education to enhance participation levels \\
\hline Complex programme & $\begin{array}{l}\text { An intervention the broadly reflects a combination of any above interventions, that } \\
\text { cannot be defined as primarily one or another for any reason. This includes } \\
\text { counselling to determine individualised activities. The combination is defined for each } \\
\text { intervention in included study tables }\end{array}$ \\
\hline
\end{tabular}




\section{Search methods}

In addition to using the population, interventions, comparators, outcomes and study design approach (PICOS), the Setting, Perspective, Phenomena of Interest, Comparison and Evaluation (SPICE) Framework $^{21}$ was used to refine the design the search methods for qualitative and grey literature exploring views and experiences of exercise and interventions as the phenomena of interest. Medical Subject Heading (MeSH) keywords were combined with free-text keywords using Boolean operators (and/or/not) to search multiple databases chosen to reflect the multidisciplinarity of this review, including but not limited to Web of Science, PubMed, BMJ Best Practice, NHS EED, CINAHL, AMED, NICAN, PsychINFO (see online supplementary material of ref. 17 for SPICE framework, complete list of databases and specific search terms). Articles included in the review were also searched for ancestral references. Grey literature was searched for by hand searching of Opengrey.eu, key journals, website searches (including Google and Google Scholar) and approaching personal contacts. An example search $\log$ is reported in online supplementary material of this publication.

\section{Selection of studies}

All identified studies from the searches were assessed by two reviewers independently for inclusion. Results were initially screened according to title and abstract, the full text of those considered suitable were then further assessed for relevance against the inclusion/exclusion criteria. Disagreement between reviewers was resolved by discussion or arbitration by a third person when necessary.

\section{Quality assessment}

The risk of bias of quantitative evidence from each included study was assessed using the Cochrane risk of bias tool in line with GRADE (Grading of Recommendations, Assessment, Development and Evaluation) approach. ${ }^{22}$ Risk of bias was rated as low, unclear or high depending on whether the randomisation sequence is adequate, randomisation is concealed, baseline characteristics and outcomes are similar in treatment and control groups, missing data were handled appropriately, experimenters were blinded, all outcome measures were reported, and the study was protected from possible contamination and any other risks of bias. The GRADE approach specifically assesses:

- Methodological flaws within the component studies

- Consistency of results across different studies

- Generalisability of research results to the wider patient base

- How effective the treatments have been shown to be When using the full GRADE approach, the evidence is not rated study by study, but a composite rating is made across studies for specific outcomes. In this review, almost all included studies were single stand-alone studies with heterogeneous interventions and a very high number of different outcome measures (these can be seen in the data extraction tables). Therefore, it was not possible to apply the full GRADE assessment for every heterogeneous outcome.

Qualitative studies were assessed with the Critical Appraisal Skills Programme (CASP) tool for qualitative research. As only one study was located, it was not possible to apply GRADE CERQual to assess the confidence in the synthesised finding. ${ }^{23}$

\section{Data abstraction}

Data were extracted by the two reviewers, including study design, participants, intervention type, outcome measures and results. Data extracted by each reviewer were combined and discrepancies were discussed and where necessary resolved by arbitration by a third person.

The intervention studies included in this review were too heterogeneous in terms of participant characteristics, intervention design and outcome measures to allow a meta-analysis. Therefore, extracted data were summarised and presented in harvest plots, which offer the possibility to present complex and diverse data within easily interpreted graphical formats, analogue to forest plots. ${ }^{24}$ These plots were constructed to indicate whether the specific intervention type (listed in table 1) used by each study was able to improve at least one measure of health or fitness (listed above). Full data extraction tables are included in the online supplementary materials.

The studies reporting interventions, including wheelchair users, were managed separately from those with 'undefined wheelchair use'; they were differentiated in harvest plots and considered separately in data analysis and synthesis.

\section{Validity, reliability and rigour}

The review has been designed to follow Cochrane methods and processes, including the use of double independent data processing and assessment of risk of bias using validated tools. None of the authors have any conflicts of interest that would affect their interpretation of evidence.

\section{RESULTS}

\section{Included studies}

Searches returned 9806 hits (excluding duplicates), of which 31 papers from 28 studies $^{25-55}$ were deemed to meet the criteria for inclusion in this review. Only one qualitative study $^{55}$ and no health economics studies that met the inclusion criteria were found. The flow chart of article screening and inclusion is in figure 1. Tables 2-4 present characteristics of all included studies, their article number (\#) and risk of bias. Of the 31 included articles, 11 (\#1-10 and \#31) reported their sample to include wheelchair users. Only seven quantitative papers were considered to be low risk of bias (articles \#3, 4, 13, $15,19,20,23)$, seven were considered to have an 


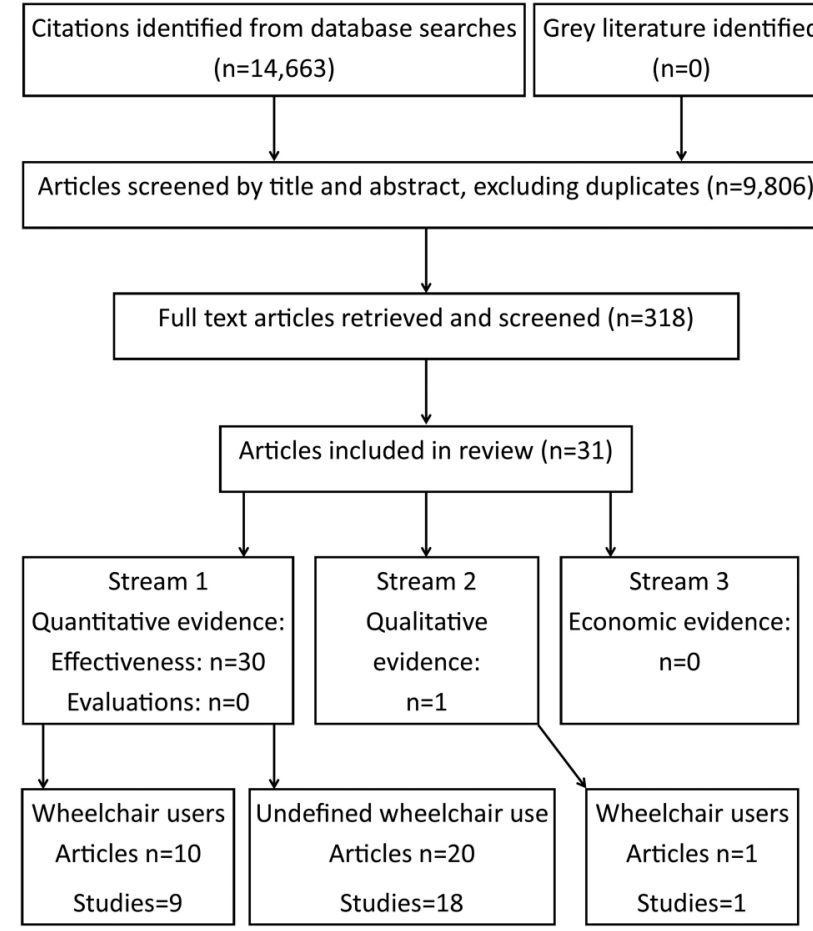

Figure 1 Flow of article screening and inclusion in this review.

unclear risk of bias (\#2,11,12,14,17,21,22), meaning 16 articles were rated as high risk of bias (\#1,5$10,16,18,24-30)$.

A wide range of interventions were used by the included studies (table 1). The most common categorisation of intervention type was 'complex' $(n=8)$, which entailed combinations of exercise modes $(\# 5,7,10,28)$ or lifestyle interventions, including counselling and individualised physical activity $(\# 3,4,6,21)$. Interestingly, the majority $(n=6)$ of these complex interventions were with 'wheelchair users'. The variability in intervention was even apparent among those categorised similarly, which often had disparate training protocols, for example, exercise intensity, duration or number of repetitions performed, and location of training. This led to variability in intervention effectiveness (reported below).

Outcome measures all fell within the categories listed in the Types of outcome measures section. However, there was little consistency in the tools or protocols used to assess each outcome type (see data extraction tables in online supplementary material). For instance, assessments of cardiovascular fitness/exercise capacity included a 6-min cycle, peak aerobic power, 9-min run, energy expenditure index and self-assessment. Mobility assessments included walking speed and distance in $30 \mathrm{~s}-2 \mathrm{~min}$, time to raise from the floor or a chair, step-up repetitions and balance stability. Standard tools were used to assess quality of life and well-being (CAPE and PEDS-QL were common), and domains D and E were frequently selected from the Gross Motor Function Measure. Similar variability existed among all other outcome types, making comparison between interventions difficult.

Sample size in the treatment group of included studies ranged from 2 to 52 , with a total of 725 children and young people reported in the included studies. Two studies included only males $(\# 1,29)$, it was not possible to determine sex distribution in four, and in the rest the sample typically consisted of $\sim 60 \%$ males. Age of participants ranged from 3 to 25 years, although 7-14 years was common. It was notable that cerebral palsy was the most frequent cause of disability and that most participants were ambulant to some extent. Gross Motor Function Classification System, where reported, was typically levels 1-3. Only four studies reported, including GMFCS level 4 or 5 . There were no major concerns about methodological limitations in the qualitative study. ${ }^{31}$

\section{Outcomes}

Positive changes in health, fitness and well-being were reported across all outcome types. Wide variability existed in effectiveness of each intervention type. Many interventions were reported to be effective in some studies, but other studies found a similar intervention type to have no effect on the specific outcome. It was noted that there were no reports of changes favouring control, or a negative change in uncontrolled trials. Additionally, none of the included articles reported adverse outcomes during or following exercise intervention.

Fitness and exercise capacity was improved by walking ( $\mathrm{n}=1 / 1$ studies), cycling $(\mathrm{n}=1 / 3)$, functional exercises with body weight $(n=1 / 2)$ and added weight (functional PRT) $(n=1 / 1)$, sports and games $(n=1 / 4)$ and complex programmes $(n=2 / 2)$ (figure 2$)$. Quality of life was improved by walking $(n=1 / 2)$, cycling $(n=1 / 2)$, PRT $(n=1 / 1)$ and functional exercises $(n=2 / 2)$ but not functional PRT $(n=0 / 1)$ or complex lifestyle programmes $(n=0 / 2)$, or the addition of music for motivation $(n=0 /$ 1) (figure 3).

Gross motor function and mobility (figures 4 and 5) were improved by programmes containing functional exercises $(n=2 / 2)$, including walking $(n=1 / 2)$ and Nintendo Wii $(n=1 / 1)$, when using only the participant's own body weight. When additional weight was added to create a functional resistance training, no effect was seen ( $\mathrm{n}=0 / 4$ studies). The only exception to this was functional resistance training at $20-50 \%$ of $1-$ repetition maximum accompanied with rhythmicallymatched music, which temporarily improved gross motor function but not mobility. Cycling preserved gross motor function in boys with Duchenne muscular dystrophy but was not effective in other groups. Resistance training was not effective to improve gross motor function or mobility.

Most intervention types ( $\mathrm{n}=8 / 15$ studies), including functional resistance training, increased strength in some studies but not others (figure 6). Walking did not 


\begin{tabular}{|c|c|c|c|c|c|c|}
\hline Article \# & Author (Year) & $\begin{array}{l}\text { Intervention type (exercise } \\
\text { mode) }\end{array}$ & Setting; nationality & $\begin{array}{l}\text { Participants: cause of impairment; } \\
\text { intervention and control } n, \% \text { male; age; } \\
\text { GMFCS (when available) }\end{array}$ & $\begin{array}{l}\text { Duration; } \\
\text { follow-up }\end{array}$ & $\begin{array}{l}\text { Risk of } \\
\text { bias }\end{array}$ \\
\hline \multicolumn{7}{|c|}{ RCTs, including wheelchair users } \\
\hline 1 & Jansen et al (2013) & Cycling: arm and peddle & $\begin{array}{l}\text { Home; the } \\
\text { Netherlands }\end{array}$ & $\begin{array}{l}\text { Duchenne muscular dystrophy; I: } 17 \text { C: } 13 \text {; } \\
100 \% \text {; range } 7-13 \text { years; late ambulatory } \\
\text { phase or wheelchair dependent }\end{array}$ & $\begin{array}{l}24 \text { weeks; } \\
24 \text { weeks }\end{array}$ & High \\
\hline $2 a$ & $\begin{array}{l}\text { Van Den Berg-Emons } \\
\text { et al (1998) }\end{array}$ & $\begin{array}{l}\text { Sport/games-based aerobic. } \\
\text { (4 times per week) }\end{array}$ & $\begin{array}{l}\text { Community, group; } \\
\text { the Netherlands }\end{array}$ & $\begin{array}{l}\text { Cerebral palsy (spastic); I: } 10 \mathrm{C}: 10 ; 55 \% \text {; } \\
\text { range } 7-13 \text { years; 'half of the children was } \\
\text { ambulant, the other half wheelchair-bound' }\end{array}$ & $\begin{array}{l}9 \text { months; } \\
3 \text { months }\end{array}$ & Unclear \\
\hline $2 b$ & $\begin{array}{l}\text { Van Den Berg-Emons } \\
\text { et al } 1998\end{array}$ & $\begin{array}{l}\text { Sport/games-based aerobic. } \\
\text { ( } 2 \text { times per week) }\end{array}$ & $\begin{array}{l}\text { Community, group; } \\
\text { the Netherlands }\end{array}$ & $\begin{array}{l}\text { Cerebral palsy (spastic); I: } 9 \text { C: } 9 \text {; unknown\%; } \\
\text { range } 7-13 \text { years; 'half of the children was } \\
\text { ambulant, the other half wheelchair-bound' }\end{array}$ & 9 months; - & Unclear \\
\hline 3 & $\begin{array}{l}\text { Van Wely et al (2014a) } \\
\text { (part of same study as } \\
\# 4)\end{array}$ & $\begin{array}{l}\text { Complex: Lifestyle } \\
\text { counselling and fitness } \\
\text { training }\end{array}$ & $\begin{array}{l}\text { Combined home and } \\
\text { supervised group; } \\
\text { the Netherlands }\end{array}$ & $\begin{array}{l}\text { Cerebral palsy; I: } 23 \text { C: } 23 ; 57 \% \text {; range } \\
\text { 7-13 years; GMFCS } 1-3\end{array}$ & $\begin{array}{l}6 \text { months; } \\
6 \text { months }\end{array}$ & Low \\
\hline 4 & $\begin{array}{l}\text { Van Wely et al (2014b) } \\
\text { (part of same study as } \\
\# 3 \text { ) }\end{array}$ & $\begin{array}{l}\text { Complex: Lifestyle } \\
\text { counselling and fitness } \\
\text { training }\end{array}$ & $\begin{array}{l}\text { Combined home and } \\
\text { supervised group; } \\
\text { the Netherlands }\end{array}$ & $\begin{array}{l}\text { Cerebral palsy; I: } 23 \text { C: } 23 ; 57 \% \text {; range } \\
\text { 7-13 years; GMFCS 1-3 }\end{array}$ & $\begin{array}{l}6 \text { months; } \\
6 \text { months }\end{array}$ & Low \\
\hline \multicolumn{7}{|c|}{ Non-RCTs, including wheelchair users } \\
\hline 5 & Andrade et al (1991) & $\begin{array}{l}\text { Complex programme: PRT } \\
\text { and cardiovascular exercise, } \\
\text { and psychosocial component }\end{array}$ & $\begin{array}{l}\text { Community, group; } \\
\text { Canada }\end{array}$ & $\begin{array}{l}\text { Spina bifida; I : } 8 \text { C: } 5 \text {; } 50 \% \text {; range } \\
7-13 \text { years; } 6 \text { 'wheelchair users' and } \\
7 \text { 'community ambulatory' }\end{array}$ & 10 weeks; - & High \\
\hline 6 & Buffart et al (2010) & $\begin{array}{l}\text { Complex: Lifestyle } \\
\text { counselling and personalised } \\
\text { activities }\end{array}$ & $\begin{array}{l}\text { Mixture of home and } \\
\text { supervised; the } \\
\text { Netherlands }\end{array}$ & $\begin{array}{l}\text { A 17-year-old male with myelomeningocele } \\
\text { and hydrocephalus, non-functional ambulator } \\
\text { and a 23-year-old female with unilateral } \\
\text { cerebral palsy, GMFCS } 1\end{array}$ & 10 weeks; - & High \\
\hline 7 & $\begin{array}{l}\text { Fragala-Pinkham et al } \\
\text { (2005) }\end{array}$ & $\begin{array}{l}\text { Complex programme: PRT } \\
\text { and aerobic exercise. }\end{array}$ & $\begin{array}{l}\text { Group supervised } \\
\text { phase followed by } \\
\text { home phase; USA }\end{array}$ & $\begin{array}{l}\text { Physical or other developmental disabilities; } \\
\text { group phase: } 9 \text { home phase: } 7 ; 78 \% \text {; range } \\
5-9 \text { years; GMFCS } 1-3\end{array}$ & $\begin{array}{l}14 \text { weeks group; } \\
12 \text { weeks home }\end{array}$ & High \\
\hline 8 & Gordon et al (2013) & Nintendo Wii & Supervised; Jamaica & $\begin{array}{l}\text { Cerebral palsy; I: } 7 \text { C: }- \text {; } 57 \% \text {; range } \\
\text { 9-12 years; } 4 \text { wheelchair users. }\end{array}$ & 6 weeks; - & High \\
\hline 9 & $\begin{array}{l}\text { Odman and Oberg } \\
(2005)\end{array}$ & $\begin{array}{l}\text { Functional exercises } \\
\text { (combined Lemo }+ \text { move } \\
\text { and walk interventions) }\end{array}$ & $\begin{array}{l}\text { Group, location } \\
\text { unclear; Sweden }\end{array}$ & $\begin{array}{l}\text { Cerebral palsy; I: } 52 \text { C: -; 59\%; unknown \%; } \\
\text { range 3-16 years; GMFCS 1-5 }\end{array}$ & $\begin{array}{l}4 \text { weeks intensive; } \\
1 \text { year voluntary } \\
\text { participation }\end{array}$ & High \\
\hline 10 & Unnithan, 2007 & $\begin{array}{l}\text { Complex programme: PRT } \\
\text { and walking }\end{array}$ & Group; Greece & $\begin{array}{l}\text { Cerebral palsy; I: } 7 \text {; C: } 6 \text {; } 31 \% \text {; range } \\
14-18 \text { years; GMFM (D\&E) } \sim 30 \%\end{array}$ & 12 weeks; - & High \\
\hline
\end{tabular}


Table 3 Characteristics and risk of bias of included quantitative studies with 'undefined wheelchair use'

\begin{tabular}{|c|c|c|c|c|c|c|}
\hline Article \# & Author (Year) & $\begin{array}{l}\text { Intervention type (exercise } \\
\text { mode) }\end{array}$ & Setting; nationality & $\begin{array}{l}\text { Participants: cause of impairment; } \\
\text { intervention and control n, \% male; age; } \\
\text { GMFCS (when available) }\end{array}$ & $\begin{array}{l}\text { Duration; } \\
\text { follow-up }\end{array}$ & $\begin{array}{l}\text { Risk of } \\
\text { bias }\end{array}$ \\
\hline \multicolumn{7}{|c|}{ RCT with population with undefined wheelchair use } \\
\hline 11 & $\begin{array}{l}\text { Choi et al. } \\
(2016)\end{array}$ & $\begin{array}{l}\text { Spirometer exercise with versus } \\
\text { without additional therapy }\end{array}$ & $\begin{array}{l}\text { Mixture of individual } \\
\text { and supervised in } \\
\text { clinic; Korea }\end{array}$ & $\begin{array}{l}\text { Cerebral palsy; I: } 25 \text { C: } 23 ; 52 \% \text {; range: } \\
\text { 8-15 years; GMFCS 1-5 }\end{array}$ & 4 weeks; - & Unclear \\
\hline 12 & $\begin{array}{l}\text { De Groot et al } \\
\text { (2011) }\end{array}$ & Walking & $\begin{array}{l}\text { Home, supervised; the } \\
\text { Netherlands }\end{array}$ & $\begin{array}{l}\text { Spina Bifida; I: } 18 \text { C: } 14,56 \% \text {; mean } 10.7 \\
\text { SD 2.8 years; 'community ambulatory' }\end{array}$ & 12 weeks; - & Unclear \\
\hline 13 & $\begin{array}{l}\text { Demuth et al } \\
(2012) \\
\text { (part of same } \\
\text { study as \#15) }\end{array}$ & $\begin{array}{l}\text { Cycling: using a complex structure } \\
\text { of strengthening and } \\
\text { cardiorespiratory phases in each } \\
\text { session }\end{array}$ & Clinic; USA & $\begin{array}{l}\text { Cerebral palsy (spastic diplegic); I: } 28 \text { C: } 29 \text {, } \\
48 \% \text {; range } 7-18 \text { years; GMFCS } 1-3\end{array}$ & 12 weeks; - & Low \\
\hline 14 & Dodd, 2003 & PRT with functional exercises & Home; Australia & $\begin{array}{l}\text { Cerebral palsy (spastic diplegic); I: } 11 \text { C: } 10 \text {; } \\
48 \% \text {; range 8-18 years; GMFCS 1-3 }\end{array}$ & 6 weeks; 12 weeks & Unclear \\
\hline 15 & $\begin{array}{l}\text { Fowler et al } \\
(2010) \\
\text { (part of same } \\
\text { study as \#13) }\end{array}$ & $\begin{array}{l}\text { Cycling: using a complex structure } \\
\text { of strengthening and } \\
\text { cardiorespiratory phases in each } \\
\text { session }\end{array}$ & Clinic; USA & $\begin{array}{l}\text { Cerebral palsy (spastic diplegic); I: } 26 \text { C: } 26 \text {, } \\
48 \% \text {; range } 7-18 \text { years; GMFCS } 1-3\end{array}$ & 12 weeks; - & Low \\
\hline $16 a$ & $\begin{array}{l}\text { Gates et al } \\
(2012)\end{array}$ & Walking & Home; USA & $\begin{array}{l}\text { Cerebral palsy (spastic bilateral); I: } 14 \text { C: }- \text {; } \\
54 \% \text {; range } 6-13 \text { years; GMFCS } 2-4\end{array}$ & 12 weeks; 4 weeks & High \\
\hline $16 b$ & $\begin{array}{l}\text { Gates et al } \\
\text { (2012) }\end{array}$ & $\begin{array}{l}\text { PRT (including some functional } \\
\text { exercises) }\end{array}$ & Home; USA & $\begin{array}{l}\text { Cerebral palsy (spastic bilateral); I: } 12 \text { C: }- \text {; } \\
54 \% \text {; range } 7-13 \text { years; GMFCS } 2-4\end{array}$ & 12 weeks; 4 weeks & High \\
\hline 17 & $\begin{array}{l}\text { Katz-Leurer } \\
\text { et al (2009) }\end{array}$ & Functional exercises & $\begin{array}{l}\text { Home with weekly } \\
\text { phone support; Israel }\end{array}$ & $\begin{array}{l}\text { Traumatic brain injury or cerebral palsy; I: } 8 \text {, } \\
\text { C: } 10 ; 70 \% \text {; range } 7-13 \text { years; GMFCS } 1-2\end{array}$ & $\begin{array}{l}6 \text { weeks; } 6 \text { weeks } \\
\text { for intervention } \\
\text { group only }\end{array}$ & Unclear \\
\hline 18 & $\begin{array}{l}\text { Maher et al } \\
(2010)\end{array}$ & Education (internet-based) & Home; Australia & $\begin{array}{l}\text { Cerebral palsy; I: } 20 \text { C: } 21 ; 63 \% \text {; range } \\
11-17 \text { years; GMFCS 1-3 }\end{array}$ & $\begin{array}{l}10 \text { weeks; } \\
10 \text { weeks }\end{array}$ & High \\
\hline 19 & $\begin{array}{l}\text { Scholtes et al } \\
(2010) \\
\text { (part of same } \\
\text { study as \#20) }\end{array}$ & PRT with functional exercises & $\begin{array}{l}\text { Community, small } \\
\text { groups; the } \\
\text { Netherlands }\end{array}$ & $\begin{array}{l}\text { Cerebral palsy (spastic); I: } 24 \text { C: } 25 ; 59 \% \text {; } \\
6-13 \text { years; GMFCS } 1-3\end{array}$ & 12 weeks; 6 weeks & Low \\
\hline 20 & $\begin{array}{l}\text { Scholtes et al } \\
\text { (2012) } \\
\text { (part of same } \\
\text { study as \#19) }\end{array}$ & PRT with functional exercises & $\begin{array}{l}\text { Community, small } \\
\text { groups; the } \\
\text { Netherlands }\end{array}$ & $\begin{array}{l}\text { Cerebral palsy (spastic); I: } 24 \text { C: } 25 ; 59 \% \text {; } \\
6-13 \text { years; GMFCS } 1-3\end{array}$ & 12 weeks; 6 weeks & Low \\
\hline 21 & $\begin{array}{l}\text { Slaman et al } \\
(2014)\end{array}$ & $\begin{array}{l}\text { Complex: Lifestyle; counselling and } \\
\text { cardiopulmonary fitness. }\end{array}$ & $\begin{array}{l}\text { Combined supervised } \\
\text { in centre and home; } \\
\text { the Netherlands }\end{array}$ & $\begin{array}{l}\text { Cerebral palsy; I: } 17 \text { C: } 19 ; 90 \% \text {; range } \\
\text { 16-25 years; GMFCS 1-5 }\end{array}$ & 6 months; 6 months & Unclear \\
\hline 22 & $\begin{array}{l}\text { Verschuren } \\
\text { et al (2007) }\end{array}$ & Functional exercises & $\begin{array}{l}\text { Community, group; the } \\
\text { Netherlands }\end{array}$ & $\begin{array}{l}\text { Cerebral palsy (spastic); I: } 32 \text { C: } 33 ; 65 \% \text {; } \\
\text { range } 7-18 \text { years; GMFCS 1-2 }\end{array}$ & 8 months; - & Unclear \\
\hline 23 & $\begin{array}{l}\text { Wang et al } \\
(2013)\end{array}$ & Motivation: music during PRT & Home; Taiwan & $\begin{array}{l}\text { Cerebral palsy; I: } 18 \text { C: } 18 ; 75 \% ; 5-13 \text { years; } \\
\text { GMFCS } 1-3\end{array}$ & 6 weeks; 12 weeks & Low \\
\hline
\end{tabular}

\section{$R C T$ with population with undefined wheelchair use} (2016)

Spirometer exercise with versus

Home, supervised; the

Netherlands

(2011)

(2012)

part of same

study as \#15)

Fowler et al

(2010)

(part of same

tudy as \#13)

(2012)

(2012)

(2010)

(2012)

et

cardiopulmonary fitness.

Community, group; the

Netherlands

(2013) 


\begin{tabular}{|c|c|c|c|c|c|c|}
\hline Article \# & Author (Year) & $\begin{array}{l}\text { Intervention type (exercise } \\
\text { mode) }\end{array}$ & Setting; nationality & $\begin{array}{l}\text { Participants: cause of impairment; } \\
\text { intervention and control n, \% male; age; } \\
\text { GMFCS (when available) }\end{array}$ & $\begin{array}{l}\text { Duration; } \\
\text { follow-up }\end{array}$ & $\begin{array}{l}\text { Risk of } \\
\text { bias }\end{array}$ \\
\hline \multicolumn{7}{|c|}{ Non-RCT with population with undefined wheelchair use } \\
\hline 24 & $\begin{array}{l}\text { Blundell et al } \\
\text { (2003) }\end{array}$ & Functional exercises & Group; Australia & $\begin{array}{l}\text { Cerebral palsy; I: } 7 \text { C: -; } 88 \% \text { range } \\
4-8 \text { years; Motor-Assessment Scale, } \\
\text { sit-to-stand item } 1.5\end{array}$ & 4 weeks; 8 weeks & High \\
\hline 25 & $\begin{array}{l}\text { Damiano et al } \\
\text { (1995) }\end{array}$ & PRT & $\begin{array}{l}\text { Setting unclear; the } \\
\text { USA }\end{array}$ & $\begin{array}{l}\text { Cerebral palsy (spastic diplegia); I: } 14 \text { C: -; } \\
71 \% \text {; range } 6-14 \text { years; } 11 \text { independent } \\
\text { ambulators, } 3 \text { required hand-held assistive } \\
\text { devices }\end{array}$ & 6 weeks; - & High \\
\hline 26 & $\begin{array}{l}\text { Chen et al } \\
\text { (2012) }\end{array}$ & Cycling (in virtual reality) & Home; Taiwan & $\begin{array}{l}\text { Cerebral palsy; I: } 13 \text { C: } 14 ; 68 \% \text {; range } \\
6-12 \text { years; GMFCS } 1-2\end{array}$ & 12 weeks & High \\
\hline 27 & $\begin{array}{l}\text { Crompton et al } \\
\text { (2007) }\end{array}$ & PRT with functional exercises & Clinic, group; Australia & $\begin{array}{l}\text { Cerebral palsy; I: } 7 \text { C: } 6 ; 40 \% \text {; range } \\
\text { 6-14 years; GMFCS } 1-3\end{array}$ & 6 weeks; 6 weeks & High \\
\hline 28 & $\begin{array}{l}\text { Kelly and Legg } \\
\text { (2009) }\end{array}$ & $\begin{array}{l}\text { Complex programme: PRT, aerobic } \\
\text { exercise and sports }\end{array}$ & $\begin{array}{l}\text { Community, group; } \\
\text { Canada }\end{array}$ & $\begin{array}{l}\text { Cerebral palsy; I: } 5 \text { C: -; unknown \%; range } \\
\text { 8-12 years; GMFCS 1-2 }\end{array}$ & 10 weeks & High \\
\hline 29 & $\begin{array}{l}\text { Lancioni et al } \\
\text { (2004) }\end{array}$ & Motivation: feedback & Home centre; Europe & $\begin{array}{l}\text { Profound disability range; } 2 \text { boys, } 15.6 \text { and } \\
22.1 \text { years; not reported }\end{array}$ & $\sim 7$ months & High \\
\hline $30 \mathrm{a}$ & $\begin{array}{l}\text { Shinohara, } \\
2002\end{array}$ & Cycling: peddle & Unclear; Japan & $\begin{array}{l}\text { Cerebral palsy; I: } 6 \text {, C: -; range } 13-15 \text { years; } \\
\text { not reported, but could peddle a bike. }\end{array}$ & $16.7 \pm 4.7$ weeks; - & High \\
\hline $30 \mathrm{~b}$ & $\begin{array}{l}\text { Shinohara, } \\
2002\end{array}$ & Cycling: arm & Unclear; Japan & $\begin{array}{l}\text { Cerebral palsy; I: } 5, \text { C: -; unknown\%; range } \\
11-16 \text { years; not reported, but could not } \\
\text { peddle a bike. }\end{array}$ & $12.7 \pm 6.3$ weeks; - & High \\
\hline
\end{tabular}




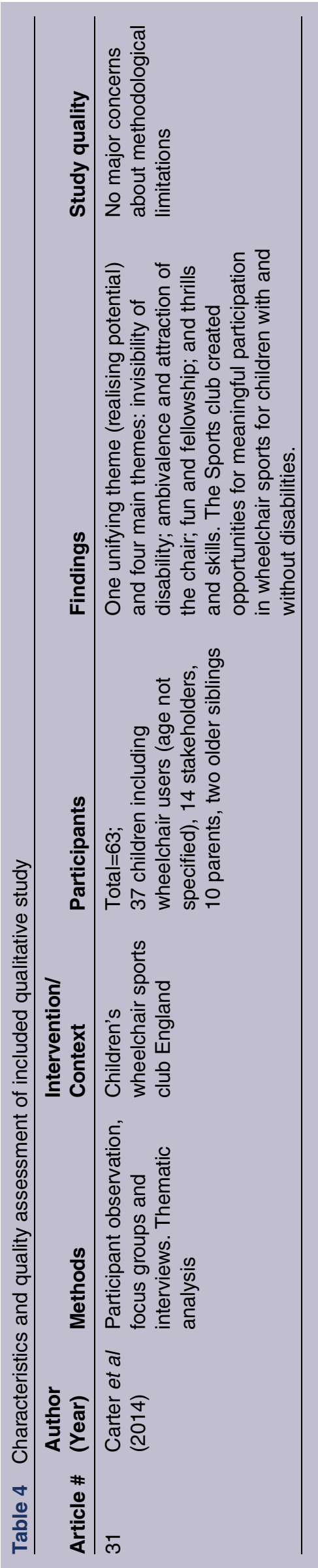

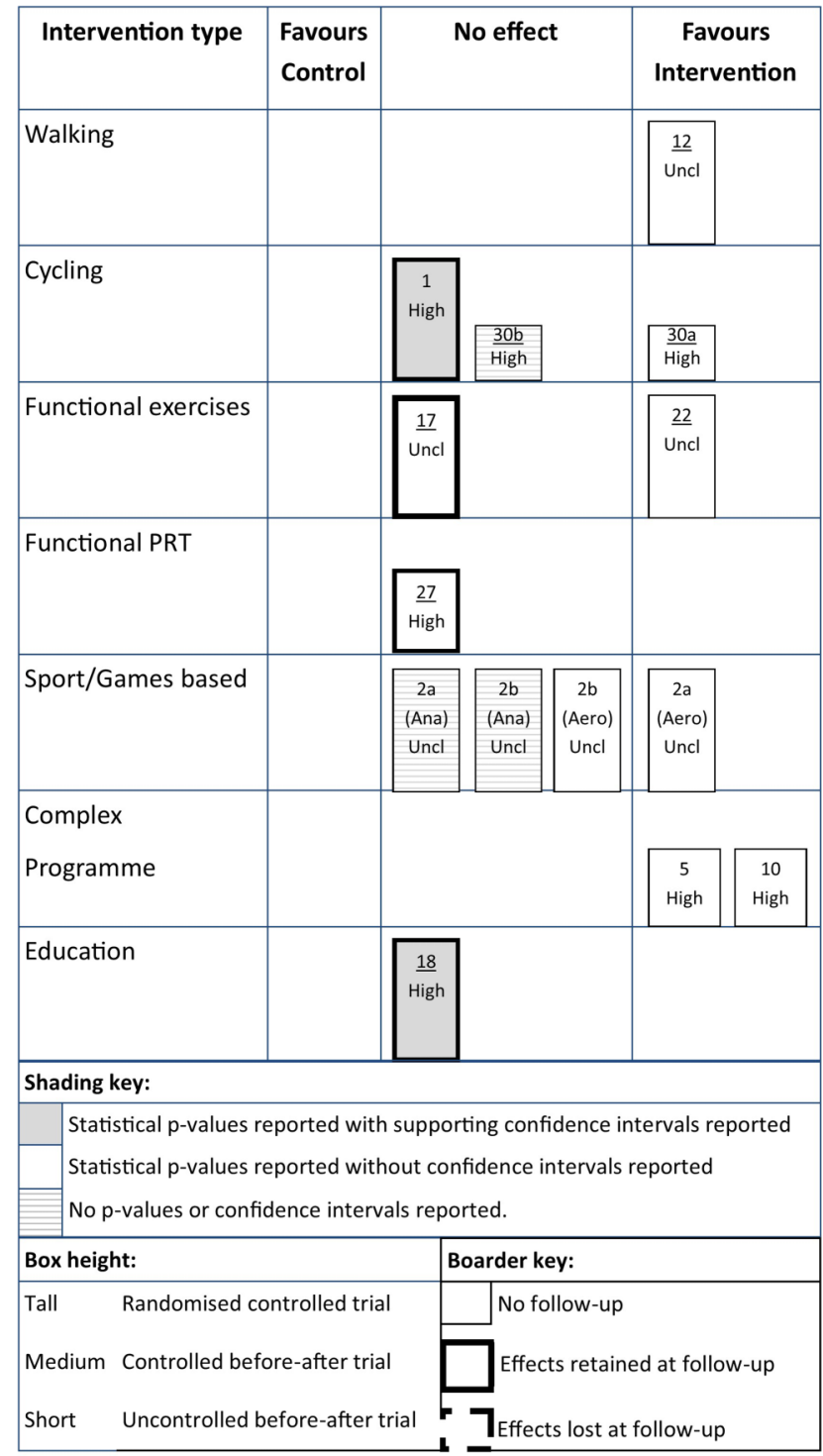

Figure 2 Harvest plot of intervention effects on fitness and exercise capacity. Each box represents the findings of a single article, and contains the article number, which is underlined for studies with undefined wheelchair use, and the risk of bias rating (High, Unclear or Low). Article 2 measured aerobic (Aero) and anaerobic (Ana) fitness, and these are distinguished below by article number.

to increase strength $(n=1 / 1)$. The addition of music during PRT did not increase strength any more than PRT alone $(n=1 / 1)$.

Changes in physical activity levels were variable in response to different interventions (figure 7 ). What was interesting was that articles \#4 and \#21, which implemented the same complex intervention of counselling and individualised physical activities, found increased self-reported physical activity levels, but detected no change in objectively measured physical activity levels.

Three RCTs quantifying changes in body composition were identified, all were considered to present an unclear risk of bias. Article \#2 delivered a sports and games based intervention to wheelchair users four-times 


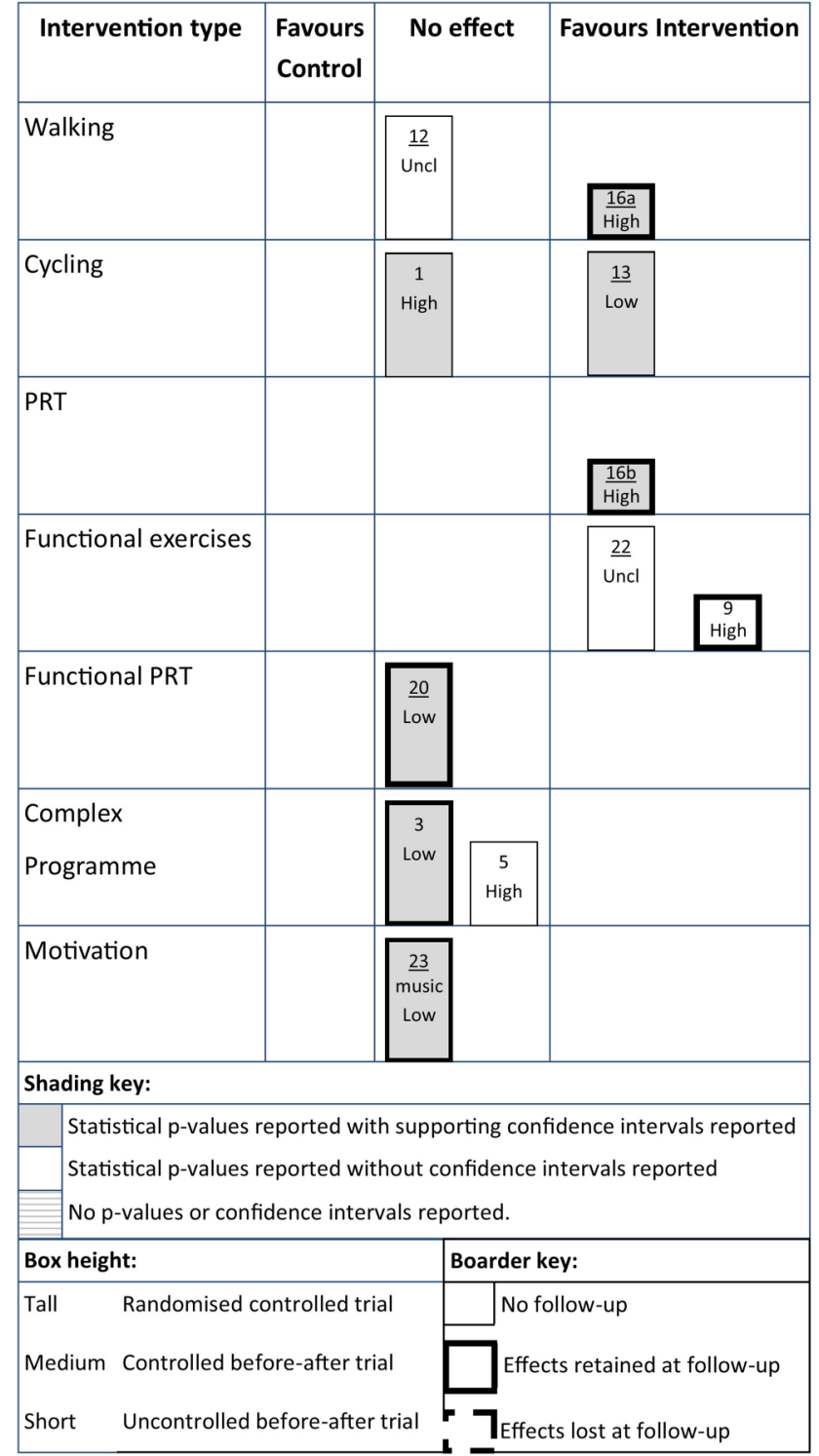

Figure 3 Harvest plot of intervention effects on quality of life and attitudes. Each box represents the findings of a single article, and contains the article number, which is underlined for studies with undefined wheelchair use, and the risk of bias rating (high, unclear or low).

per week for 3 months (\#2a) and two-times per week for 9 months (\#2b); in both cases fat mass increased in the control group $(\mathrm{p}<0.05)$ but did not change in the exercise group ( $p$ values not reported). However, only in the two times per week intervention was a significant interaction detected $(p<0.05)$. A follow-up was performed in the four times per week arm and fat mass increased similarly in the experimental and control groups. Articles \#12 and \#22 used walking and functional open kineticchain exercises, respectively, with undefined wheelchair users and found no improvements postintervention.

One study (\#10) measured resting respiratory exchange ratio as an indicator of metabolic function. Following a complex programme of resistance training and walking, no change was found ( $p$ value not

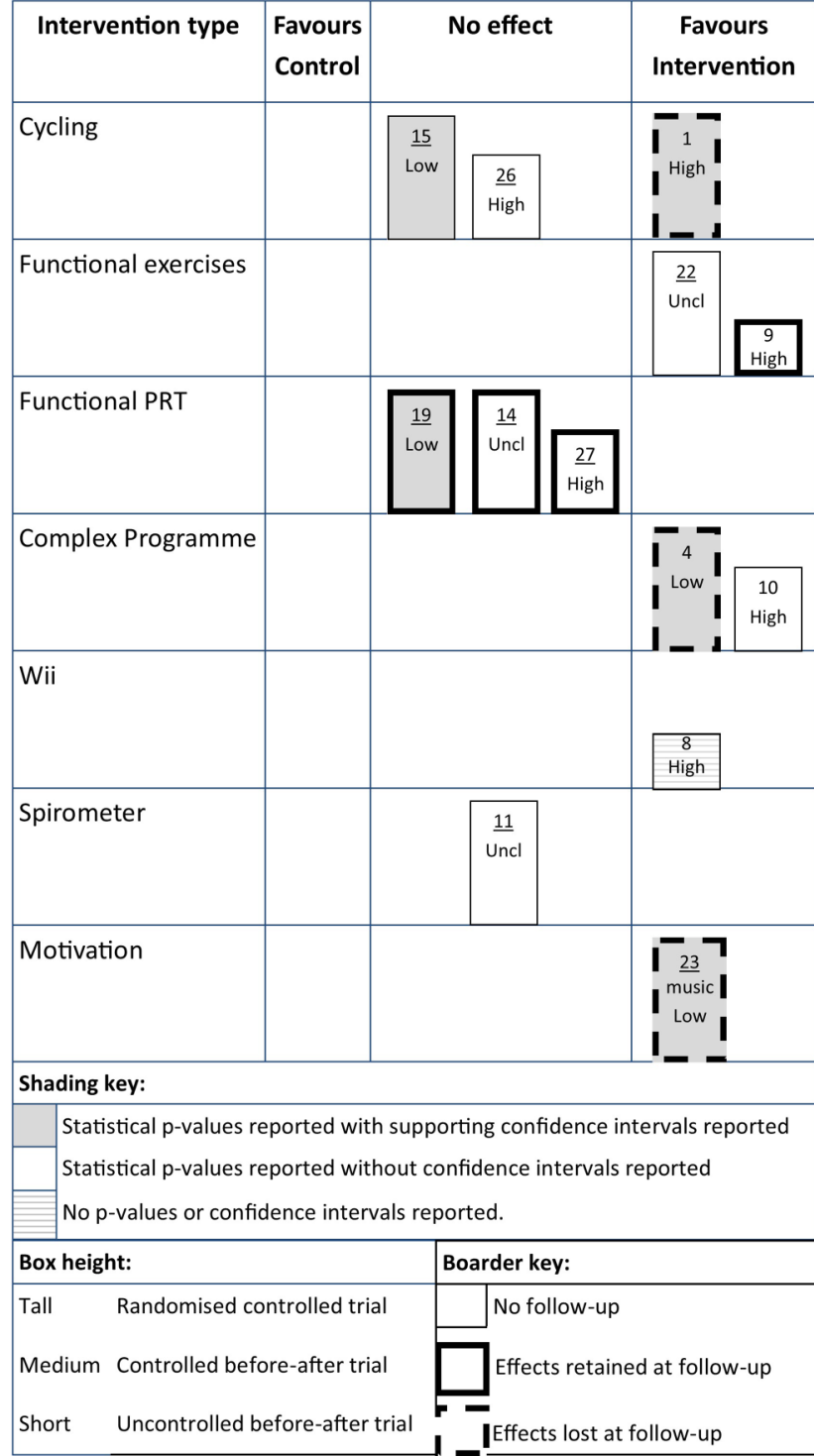

Figure 4 Harvest plot of intervention effects on gross motor function. Each box represents the findings of a single article, and contains the article number, which is underlined for studies with undefined wheelchair use, and the risk of bias rating (high, unclear or low).

reported). This study was considered to be at high risk of bias.

In an RCT with a sample of undefined wheelchair use, article \#11 found spirometer training significantly improved multiple components of respiratory function.

When considering only the few studies that explicitly reported, including wheelchair users (\#1-10), a similar picture of high variability of intervention effectiveness generally emerges. Of note, all 'wheelchair user' studies that measured gross motor function found improvements following cycling, Wii or complex programmes (figure 4), but the only article to report improved quality of life was an uncontrolled before-after study using functional exercises (figure 3).

Fifteen $(\sim 50 \%)$ of the quantitative articles (from 13 studies) included a follow-up period of some form, 


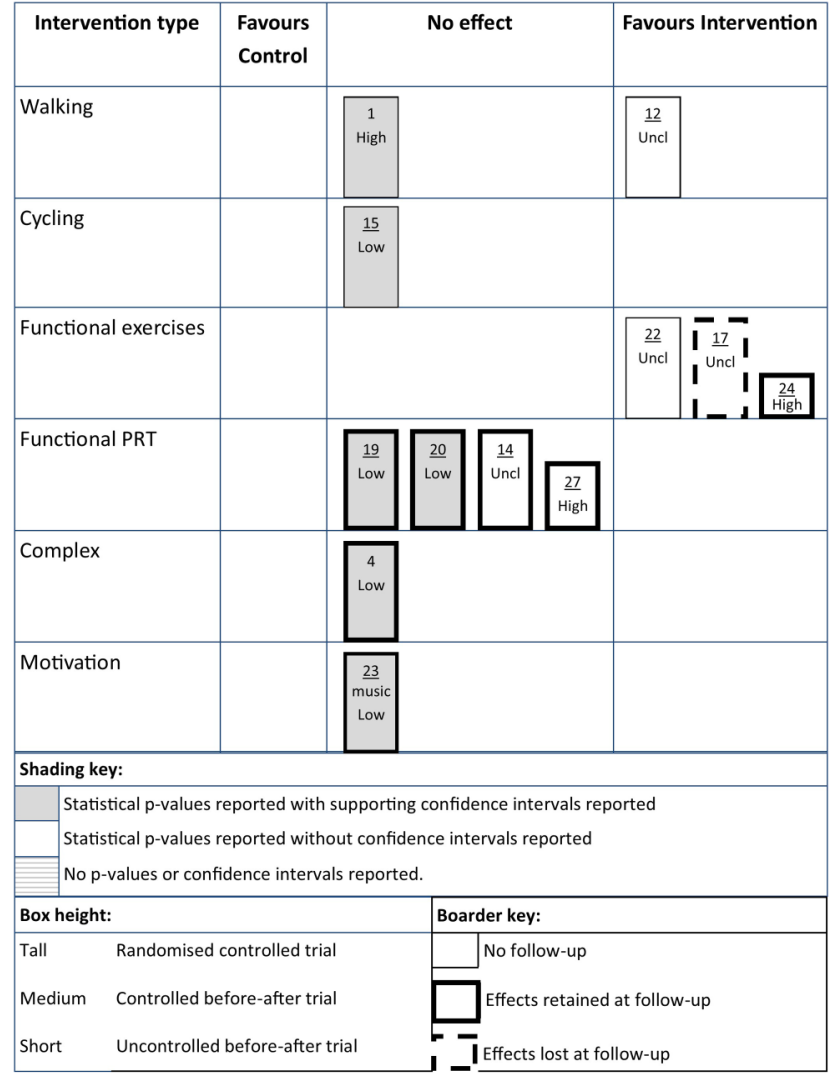

Figure 5 Harvest plot of intervention effects on ambulation and mobility. Each box represents the findings of a single article, and contains the article number, which is underlined for studies with undefined wheelchair use, and the risk of bias rating (high, unclear or low).

either complete intervention withdrawal or recommended self-directed activity. In all cases when quality of life was improved following intervention $(\# 9,16 \mathrm{a}, \mathrm{b})$ the improvements were retained at follow-up (figure 3). However, for other outcome measures, any improvements were almost all lost by follow-up.

\section{Children's experiences}

Only one study reported children's views and experiences of the benefits of attending a UK-based sports club with typically developing children. This experience contrasts to those children recruited to quantitative intervention studies where all the samples consisted of only disabled children. In addition to participating in sports, keeping fit and experiencing fun and thrills and wider social benefits, children learnt to be more independent and became more aware of what they were capable of achieving. Some children also developed a more positive relationship with their wheelchair.

\section{DISCUSSION}

This systematic review included 31 articles from 28 studies measuring a wide range of quantitative health-related, fitness-related and quality of life-related outcomes, and qualitative experiences before and after

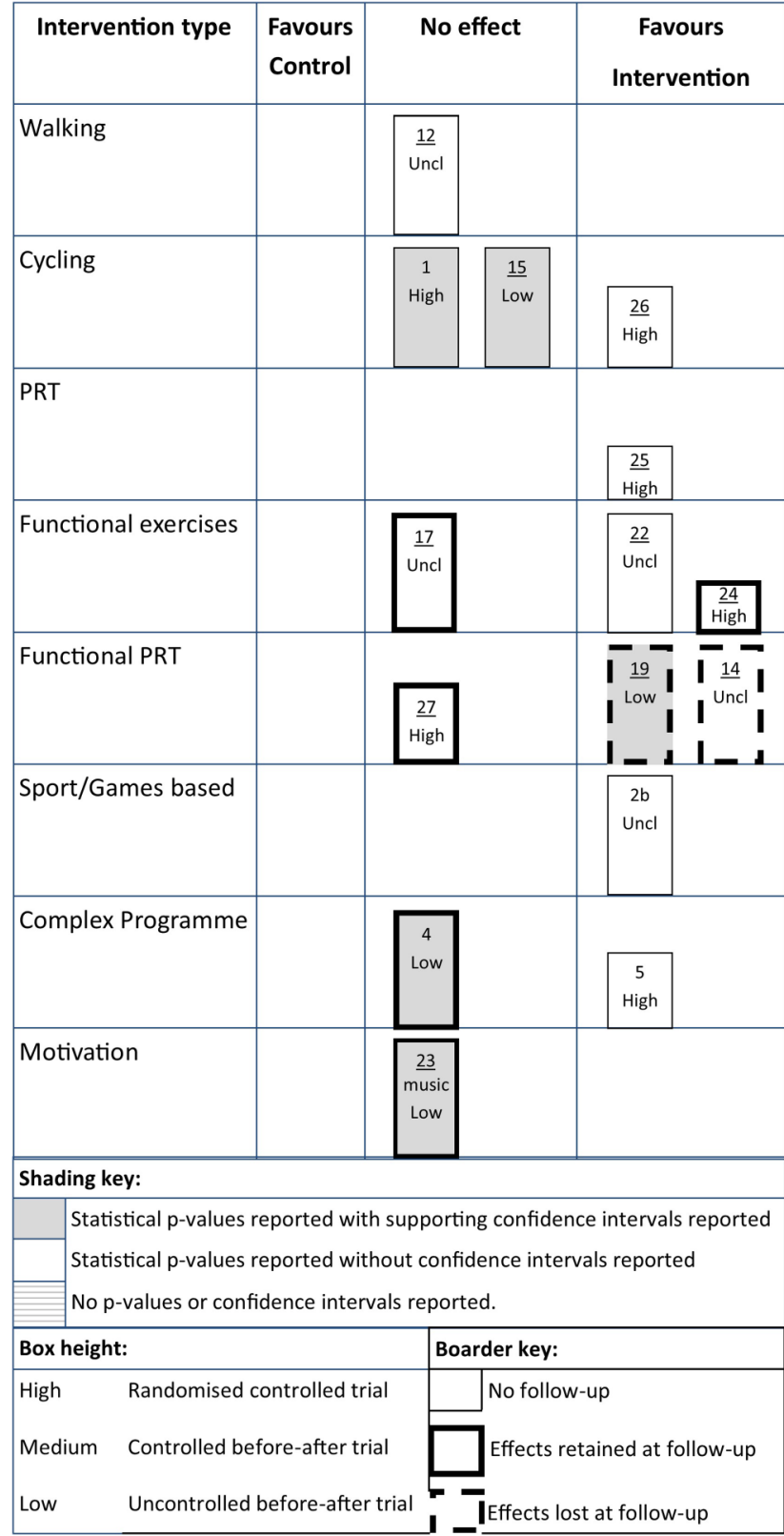

Figure 6 Harvest plot of intervention effects on muscle strength. Each box represents the findings of a single article, and contains the article number, which is underlined for studies with undefined wheelchair use, and the risk of bias rating (high, unclear or low).

exercise and physical activity interventions. These studies demonstrate that children who use wheelchairs are able to participate in various physical activity and exercise, and do so safely. Although the evidence is weak, it appears that these children can experience the same improvements in fitness, strength, mobility and quality of life as usually associated with appropriate exercise.

All intervention types were able to elicit some improvements in health, fitness and/or well-being. Conversely, most intervention types also failed to improve health, fitness and/or well-being in other 


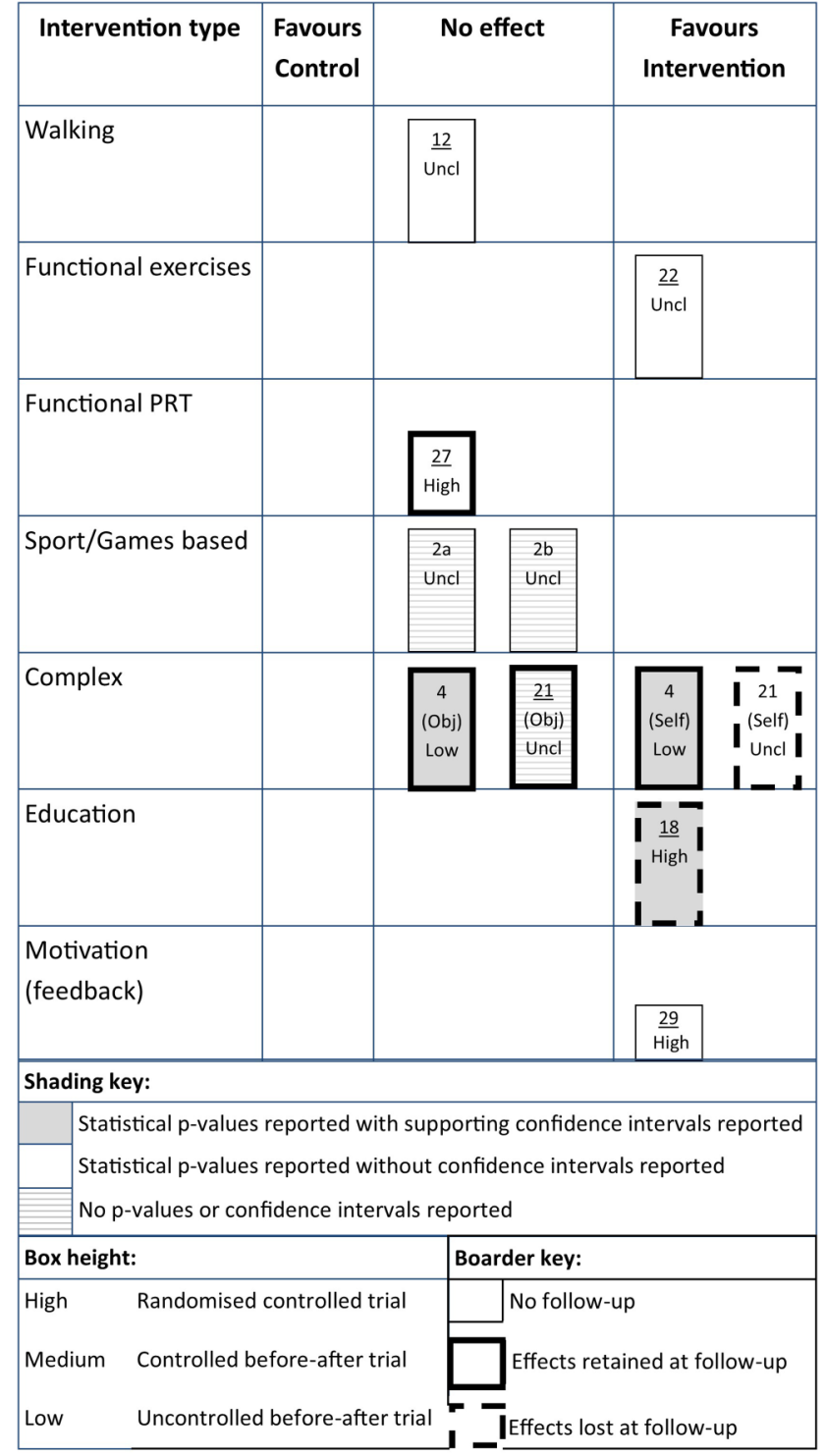

Figure 7 Harvest plot of intervention effects on muscle physical activity levels. Each box represents the findings of a single article, and contains the article number, which is underlined for studies with undefined wheelchair use, and the risk of bias rating (High, Unclear or Low). Articles 4 and 21 measured physical activity objectively (Obj) and self-reported (Self) by parents and children, these are distinguished below article number.

studies. This reflects the highly inconsistent way that interventions are designed and delivered, and outcomes are assessed. Undoubtedly, delivering physical activity interventions to children with severe mobility impairments who use wheelchairs is challenging, but investigators must make efforts to follow established exercise prescription guidance to maximise the effectiveness of interventions. Failure to do so is particularly evident in the resistance training interventions, where several studies do not meet standard recommendations. ${ }^{56}$ Indeed, in their introduction, Scholtes et al (\#20) also identified that many previous studies provided insufficient training loads or appropriate progression. Among the studies reviewed here, some used low weights $(\# 10,23)$, a high number of lifting repetitions more akin to circuit training (\#27) and achieved progression by increasing number of repetitions rather than load $(\# 10,17)$.

The evidence included in this review indicate that work is required to define appropriate primary outcome measures that are specific and applicable to the intervention and population studied. This is complex due to the multifaceted constructs of health and fitness and the heterogeneity of the samples tested, but failure to do so prevents robust evidence synthesis and identification of the most effective interventions. Best systematic review practise is to prespecify the outcomes of interest and only include evidence concerning these. GRADE can then be used to assess the overall quality of evidence within each outcome type. We were unable to apply GRADE in full due to the many different outcome measures used across studies. This, along with inconsistent and sometimes suboptimal intervention design, reflects the relative infancy of this field.

It is clear that efforts to develop appropriately designed interventions and a standardised framework for evaluating interventions consistently across different subgroups of children are required. The great heterogeneity within the current evidence makes it challenging to make detailed recommendations for policymakers and practitioners at present. Nonetheless, the evidence gathered in the present review does allow us to reach some more specific conclusions and make recommendations beyond general conclusion that physical activity is safe and appears effective.

First, it appears possible to improve the gross motor function of children who use wheelchairs by several different types of physical activity. This may reflect the great capacity this subgroup of children has for improvement, and shows the potential they may be able to achieve. However, these effects did not appear to improve self-reported quality of life. It is hard to determine whether this is because the improvement in function is not large enough or the nature of the improvements is not transferable to improve overall quality of life, or whether the quality of life tools are not sensitive to the functional improvements.

Second, if the desired outcome is to improve mobility or gross motor function, functional closed-kinetic chain exercises against the child's own body weight are required. The lack of effectiveness of resistance training suggests that strength was not the limiting factor for most children who participated in the studies reviewed. This finding is in line with a previous systematic review on physical therapy interventions for children with cerebral palsy. ${ }^{14}$ Performing functional exercise against normal body weight appears to be important for specificity of postural control strategies developed and transferability from training into actual functional tasks. However, the participants within the current evidence 
were mostly diagnosed with cerebral palsy and generally had good gross motor function and few severe cognitive impairments; therefore, they do not reflect the whole range of children who use wheelchairs. Future work should evaluate the benefits of strengthening exercises for children with more severer or different causes of mobility impairment. In addition, improving strength may be important for other activities required for independent living, for example, self-transfer in and out of wheelchair.

Third, the use of spirometer training, alongside other physical activity interventions or as part of regular therapy, may provide an effective and simple way to improve respiratory function. Given that supporting the child's posture so as not to restrict respiratory capacity in an important consideration in wheelchair fitting, this training mode may provide an effective way to increase seating options, as well as possibly health and fitness. Further work in this area is required to explore this possibility.

Forth, children experience and benefit from wider developmental and social impacts that are not currently assessed in most quantitative studies. More qualitative studies are needed to better understand how and why these impacts motivate some children to engage in exercise whereas others do not.

Most of the included articles ( $\mathrm{n}=21$, from 19 studies) consisted of group or supervised activities, and most of these were delivered or supervised by a therapist. There were few interventions based at the participants' home and fewer that integrated physical activity into daily routine and self-caring activities. This makes it difficult to evaluate programme theory (objective 2) for construct and delivery, although it is apparent that such interventions requiring intensive supervision are costly for healthcare services and likely not sustainable.

The study by Katz-Leurer, et al (\#17) developed a possibly relevant model of a home visit to deliver simple and acceptable exercises, with weekly telephone support to monitor participation, provide encouragement and ensure progression. This intervention was successful in improving a range of balance and mobility outcomes, which were consistent with other studies delivering similar exercises. Alternately, a model of short-term group-based intervention to initiate the programme followed by home-based self-directed participation may be possible, similar to that implemented by Fragala-Pinkham, et al (\#7). This study found that after 14 weeks of supervised group exercise measures of fitness, mobility and strength were improved, and many participants retained some of those improvements following 12-weeks of unsupervised, home-based participation. The Fragala-Pinkham et al study was considered to pose a high risk of bias, while the risk of bias in the Katz-Leurer et al study was unclear but with a sample with undefined wheelchair use.

A group of studies form the Netherlands $(\# 3,4,6)$ with wheelchair users and undefined wheelchair use (\#21) evaluated a complex lifestyle intervention, combining counselling/ motivational interviewing, physiotherapy and individualised physical fitness interventions. This model is instinctively appealing as it address individual barriers and facilitators to participation, as well as providing opportunities to participate in a variety of suitable physical activities. However, although some improvements were seen in gross motor function and the children's attitude to physical activity, they failed to improve objectively assessed physical activity levels, mobility, strength and most aspects of self-perceived quality of life. Moreover, the benefits that were gained were lost by follow-up. This model of intervention delivery may still warrant further development, as it appears to encompass many important elements. However, much like the intensively supervised interventions, this may be resource intensive.

Given that the National Health Service, public health, primary care, local authorities, social services, schools and wheelchair services should deliver integrated care and support to enhance health, well-being and quality of life, there are opportunities for greater integration and more cost-effective delivery of effective intervention models. A previous review by our group ${ }^{57}$ reported that wheelchair services generally met their key performance indicators by providing an appropriate wheelchair but did not commonly include lifestyle and keep-fit advice or mentoring to encourage healthy lifestyles and weight management. Using social care practitioners to deliver appropriate physical activities (such as exercise referrals dispensed by General Practitioners) that are integrated into the child's social activities, underpinned by an individualised aspirational programme theory and supported by schools to provide individually tailored keep fit activities should engender motivation and discipline from an early age.

Most studies did not report a programme theory as to how the interventions were intended to change behaviour by instilling motivation to keep fit in the short, medium or long term. Even the lifestyle interventions $(\# 3,4,6,21)$ failed to elicit long-term changes in physical activity. Given that the benefits of physical activity interventions were lost once participation ceases, long-term solutions are required.

No health economics studies that met our inclusion criteria were found, this is an important omission as these children place high demands on services across the life course. Thus, we were not able to achieve our objective of evaluating cost-effectiveness (part of objective 1). This evidence is a vital component in the development of effective and sustainable interventions and to provide evidence-based health promotion policy. In designing trials, exercise scientists need to reflect on the complex nature of delivering interventions in health services and incorporate economic and process evaluations, as well as measures of effectiveness.

The conclusions of this systematic review are limited primarily by the methodological quality of evidence, 
which was very low with concerns about high risk of bias. In many cases small sample size contributed to the high/unclear risk of bias, with few a priori or post hoc power calculations. It is of course challenging to recruit disabled children (and families) for a long-term intervention, but future efforts must ensure larger and better justified sample sizes are achieved to ensure robustness. Quality of reporting was low and did not consistently follow CONSORT reporting guidelines ${ }^{58}$ either because the trial predated CONSORT or if post-CONSORT authors did not adhere to the requirements. Overall, few estimates of precision such as CIs were reported, thereby not meeting a key CONSORT reporting requirement. The quality of design and reporting was higher in more recent studies. Overall many studies lacked rigorous methodology and awareness of best-practice frameworks for designing research, as is available in Medical Research Council Guidance for designing complex public health interventions. ${ }^{59}$ As already discussed, many studies did not prespecify a single primary outcome and measured multiple outcomes. To allow comparison and to perform a meta-analysis, questions need to be consistently refined using a PICOS structure and outcomes need to be specified and measured as outlined in trial design principles.

Children who use wheelchairs constitute a complex heterogeneous group with multiple and varied diagnoses and wide ranges of fluctuating impaired mobility. Current evidence mostly includes relatively physically able children with cerebral palsy rather than more dependent wheelchair users, as indicated by how few studies included GMFCS 4 and 5, and the number of studies using walking capacity as an outcome. Few studies included children with learning impairments and no studies included children with severe learning impairments. Therefore, the applicability of the conclusions and recommendations of the present systematic review to the full heterogeneous population with a high level of children with significant learning impairments is limited.

\section{Summary}

Current evidence indicates that children with use wheelchairs can improve their health, fitness and well-being by participating in physical activity interventions, without adverse outcomes. However, the evidence base on the most effective intervention types is weak and lacks the necessary range of theoretical underpinnings. The samples included were typically small in number and with relatively less severe mobility impairments. Consequently, it is not surprising that government policy and practice guidance is lacking and, as a consequence, insufficient attention has been paid to the fitness of children who use wheelchairs who are known to be less fit than typically developing children. Future investment and effort is required to conduct high quality trials of promising intervention types and models of delivery to establish a robust evidence base to support government and health policy to improve the fitness and well-being of children who use wheelchairs.

\section{Author affiliations}

${ }^{1}$ Research Institute for Sport and Exercise Sciences, Liverpool John Moores University, Liverpool, UK

${ }^{2}$ Health and Social Services Research and Child Health, School of Social

Sciences, Bangor University, Bangor, UK

${ }^{3}$ School of Healthcare Sciences, Bangor University, Bangor, UK

${ }^{4}$ Centre for Educational Development Appraisal and Research, University of Warwick, Coventry, UK

${ }^{5}$ Whitaker Research Ltd, Bangor, UK

Acknowledgements The authors thank Professor Rhiannon T. Edwards for advice on review design and health economics search strategy and Nathan Bray for evaluating studies that were returned from health economics searches for inclusion (both of Centre for Health Economics and Medicines Evaluation, Bangor University). They also thank Mrs Marion Poulton, Healthcare Sciences Librarian at Bangor University, for advising on the search strategy and Jacob Meaton for his significant effort in data extraction.

Contributors The review was conceived by all authors and the protocol was developed by JN, TDOB with LHS; searches were undertaken by LH; article screening was carried out by LHS, TDOB, H-PK and RPH, with mediation by $\mathrm{JN}$; risk of bias assessment was undertaken by TDOB and JN; data were interpreted by all authors; the manuscript was drafted by TDOB and critically reviewed by all authors.

Funding This review forms part of the Well MI Study funded by the National Institute for Social Care and Health Research, Wales, CRC Research Funding Scheme: Health Award (project number: RFS-12-08).

\section{Competing interests None declared.}

Provenance and peer review Not commissioned; externally peer reviewed.

Data sharing statement Full data extraction tables are available as online supplementary material.

Open Access This is an Open Access article distributed in accordance with the Creative Commons Attribution Non Commercial (CC BY-NC 4.0) license, which permits others to distribute, remix, adapt, build upon this work noncommercially, and license their derivative works on different terms, provided the original work is properly cited and the use is non-commercial. See: http:// creativecommons.org/licenses/by-nc/4.0/

\section{REFERENCES}

1. World Health Organisation. Global recommendations on physical activity for health; 5-17 years old. 2011. http://www.who.int/ dietphysicalactivity/pa/en/ (accessed Aug 2015).

2. Liou TH, Pi-Sunyer FX, Laferrère $B$. Physical disability and obesity. Nutr Rev 2005;63:321-60.

3. Maher CA, Williams MT, Olds T, et al. Physical and sedentary activity in adolescents with cerebral palsy. Dev Med Child Neurol 2007:49:450-7.

4. Buffart LM, Roebroeck ME, Rol M, et al. Triad of physical activity, aerobic fitness and obesity in adolescents and young adults with myelomeningocele. J Rehabil Med 2008;40:70-5.

5. Winnick J, Short F. The physical fitness of youngsters with spinal neuromuscular conditions. Adapt Phys Activ Q 1984;1:37-51.

6. Hoffman MD. Cardiorespiratory fitness and training in quadriplegics and paraplegics. Sports Med 1986;3:312-30.

7. Papworth Trust. Disability in the United Kingdom 2011: facts and figures. Cambridge: Papworth Trust, 2012. http://www.papworth.org. uk/downloads/factsandfigures_disabilityintheuk_july2011_110_ 110721132605.pdf (accessed Sept 2012).

8. National Institute for Health and Clinical Excellence (NICE). Public health guidance 17. Promoting physical activity for children and young people. 2009. http://guidance.nice.org.uk/PH17/Guidance/pdf/ English (accessed Oct 2012).

9. Krebs NF, Jacobson MS. American Academy of Pediatrics, Committee on Nutrition. Prevention of pediatric overweight and obesity. Pediatrics 2003;112:424.

10. Scott R. The health benefits of play and physical activity for disabled children and young people: kids briefing paper. http://www. 
sensoryintegration.org.uk/Websites/sinetwork/images/Other_images/ Health_PlayPhysicalActivitysmall2.pdf (accessed Dec 2012).

11. Novak $\mathrm{I}$, Cusick A. Home programmes in paediatric occupational therapy for children with cerebral palsy: where to start? Aust Occup Ther J 2006;53:251-64.

12. Hoare B, Imms C, Carey L, et al. Constraint induced movement therapy in the treatment of the upper limb in children with hemiplegic cerebral palsy: a Cochrane systematic review. Clin Rehabil 2007;21:675-85.

13. Snider L, Korner-Bitensky N, Kammann C, et al. Horseback riding as therapy for children with cerebral palsy: is there evidence of its effectiveness? Phys Occup Ther Pediatr 2007;27:5-23.

14. Anttila $\mathrm{H}$, Autti-Rämö I, Suoranta $\mathrm{J}$, et al. Effectiveness of physical therapy interventions for children with cerebral palsy: a systematic review. BMC Pediatr 2008;8:14.

15. Mockford M, Caulton JM. Systematic review of progressive, strength training in children and adolescents with cerebral palsy who are ambulatory. Pediatr Phys Ther 2008:20:318-33.

16. Scianni A, Butler JM, Ada L, et al. Muscle strengthening is not effective in children and adolescents with cerebral palsy: a systematic review. Aust J Physiother 2009;55:81-7.

17. O'Brien TD, Noyes J, Spencer LH, et al. 'Keep fit' interventions to improve health and fitness of children and young people who use wheelchairs: mixed-method systematic review protocol. J Adv Nurs 2014;70:2942-51.

18. Cochrane Effective Practice and Organisation of Care (EPOC) Review Group. The Data Collection Checklist. 2002. http://epoc. cochrane.org/sites/epoc.cochrane.org/files/uploads/ datacollectionchecklist.pdf (accessed Jan 2014).

19. Moher D, Liberati A, Tetzlaff J, et al. Preferred reporting items for systematic reviews and meta-analyses: the PRISMA statement. PLoS Med 2009;6:e1000097.

20. O'Brien TD, Noyes J, Spencer LH, et al. Wellbeing, health and fitness of children who use wheelchairs: Feasibility study protocol to develop child-centred 'keep-fit' exercise interventions. J Adv Nurs 2015;71:430-40.

21. Booth A, Brice A. Evidence based practice for information professionals: a handbook. London: Facet Publishing, 2003.

22. Effective Practice and Organisation of Care (EPOC). Suggested risk of bias criteria for EPOC reviews. EPOC Resources for review authors. 2012. http://epoc.cochrane.org/epoc-specific-resources-review-authors (accessed 2014).

23. Lewin $\mathrm{S}$, Glenton $\mathrm{C}$, Munthe-Kaas $\mathrm{H}$, et al. Using qualitative evidence in decision making for health and social interventions: an approach to assess confidence in findings from qualitative evidence syntheses (GRADE-CERQual). PLOS Med 2015;12:e1001895.

24. Ogilvie D, Fayter D, Petticrew M, et al. The harvest plot: a method for synthesising evidence about the differential effects of interventions. BMC Med Res Methodol 2008;8:8.

25. Jansen M, van Alfen N, Geurts AC, et al. Assisted bicycle training delays functional deterioration in boys with Duchenne muscular dystrophy: the randomized controlled trial "No use is disuse". Neurorehabil Neural Repair 2013:27:816-27.

26. van den Berg-Emons RJ, van Baak MA, Speth L, et al. Physical training of school children with spastic cerebral palsy: effects on daily activity, fat mass and fitness. Int $J$ Rehabil Res 1998;21:179-94.

27. van Wely L, Balemans ACJ, Becher JG, et al. The effectiveness of a physical activity stimulation programme for children with cerebral palsy on social participation, self-perception and quality of life: a randomized controlled trial. Clin Rehabil 2014:28:972-82.

28. van Wely L, Balemans ACJ, Becher JG, et al. Physical activity stimulation program for children with cerebral palsy did not improve physical activity: a randomised trial. J Physiother 2014;60:40-9.

29. Andrade C, Kramer J, Garber M, et al. Changes in self-concept, cardiovascular endurance and muscular strength of children with spina bifida aged 8 to 13 years in response to a 10 week physical-activity programme: a pilot study. Child Care Health Dev 1991:17:183-96.

30. Buffart LM, van den Berg-Emons RJ, van Mechelen W, et al. Promoting physical activity in an adolescent and a young adult with physical disabilities. Disabil Health J 2010;3:86-92.

31. Fragala-Pinkham MA, Haley SM, Rabin J, et al. A fitness program for children with disabilities. Phys Ther 2005;85:1182-200.

32. Gordon C, Roopchand-Martin S, Gregg A. Potential of the Nintendo Wiit ${ }^{\mathrm{TM}}$ as a rehabilitation tool for children with cerebral palsy in a developing country: a pilot study. Physiotherapy 2012;98:238-42.

33. Odman P, Oberg B. Effectiveness of intensive training for children with cerebral palsy - a comparison between child and youth rehabilitation and conductive education. J Rehabil Med 2005;37:263-70.
34. Unnithan VB, Katsimanis G, Evangelinou C, et al. Effect of strength and aerobic training in children with cerebral palsy. Med Sci Sports Exerc 2007;39:1902-9.

35. Choi JY, Rha DW, Park ES. Change in pulmonary function after incentive spirometer exercise in children with spastic cerebral palsy: a randomized controlled study. Yonsei Med $J$ 2016:57:769-75.

36. de Groot JF, Takken T, van Brussel M, et al. Randomized controlled study of home-based treadmill training for ambulatory children with spina bifida. Neurorehabil Neural Repair 2011;25:597-606.

37. Demuth SK, Knutson LM, Fowler EG. The PEDALS stationary cycling intervention and health-related quality of life in children with cerebral palsy: A randomized controlled trial. Dev Med Child Neurol 2012;54:654-61.

38. Dodd KJ, Taylor NF, Graham HK. A randomized clinical trial of strength training in young people with cerebral palsy. Dev Med Child Neurol 2003;45:652-7.

39. Fowler EG, Knutson LM, Demuth SK, et al. Pediatric endurance and limb strengthening (PEDALS) for children with cerebral palsy using stationary cycling: a randomized controlled trial. Phys Ther 2010;90:367-81.

40. Gates PE, Banks D, Johnston TE, et al. Randomized controlled trial assessing participation and quality of life in a supported speed treadmill training exercise program versus a strengthening program for children with cerebral palsy. $J$ Pediatr Rehabil Med 2012;5:75-88.

41. Katz-Leurer $\mathrm{M}$, Rotem $\mathrm{H}$, Keren $\mathrm{O}$, et al. The effects of a 'home-based' task-oriented exercise programme on motor and balance performance in children with spastic cerebral palsy and severe traumatic brain injury. Clin Rehabil 2009;23:714-24.

42. Maher CA, Williams MT, Olds T, et al. An internet-based physical activity intervention for adolescents with cerebral palsy: a randomized controlled trial. Dev Med Child Neurol 2010;52:448-55.

43. Scholtes VA, Becher JG, Comuth A, et al. Effectiveness of functional progressive resistance exercise strength training on muscle strength and mobility in children with cerebral palsy: a randomized controlled trial. Dev Med Child Neurol 2010;52:e107-13.

44. Scholtes VA, Becher JG, Janssen-Potten YJ, et al. Effectiveness of functional progressive resistance exercise training on walking ability in children with cerebral palsy: a randomized controlled trial. Res Dev Disabil 2012;33:181-8.

45. Slaman J, Roebroeck M, Dallmijer A, et al. Can a lifestyle intervention programme improve physical behaviour among adolescents and young adults with spastic cerebral palsy? A randomized controlled trial. Dev Med Child Neurol 2015;57:159-66.

46. Verschuren $\mathrm{O}$, Ketelaar M, Gorter JW, et al. Exercise training program in children and adolescents with cerebral palsy. Arch Pediatr Adolesc Med 2007;161:1075-81.

47. Wang TH, Peng YC, Chen YL, et al. A home-based program using patterned sensory enhancement improves resistance exercise effects for children with cerebral palsy: a randomized controlled trial. Neurorehabil Neural Repair 2013:27:684-94.

48. Blundell SW, Sheperd RB, Dean CM, et al. Functional strength training in cerebral palsy: a pilot study of a group circuit training class for children aged 4-8 years. Clin Rehabil 2003;17:48-57.

49. Damiano DL, Vaughan CL, Abel MF. Muscle response to heavy resistance exercise in children with spastic cerebral palsy. Dev Med Child Neurol 1995;37:731-9.

50. Chen $\mathrm{CL}$, Hong WH, Cheng HY, et al. Muscle strength enhancement following home-based virtual cycling training in ambulatory children with cerebral palsy. Res Dev Disabil 2012;33:1087-94

51. Crompton J, Imms C, McCoy AT, et al. Group-based task-related training for children with cerebral palsy: a pilot study. Phys Occup Ther Pediatr 2007;27:43-65.

52. Kelly M, Legg D. On-land community-based aerobic and strength training program for children with cerebral palsy. Eur J Adapt Phys Act 2009:2:7-20.

53. Lancioni GE, Singh NN, O'Reilly MF, et al. Use of simple exercise tools by students with multiple disabilities: Impact of automatically delivered stimulation on activity level and mood. J Dev Phys Disabil 2004;16:171-8.

54. Shinohara TA, Suzuki N, Oba M, et al. Effect of exercise at the AT point for children with cerebral palsy. Bull NYU Hosp Jt Dis 2002;61:63-7.

55. Carter B, Grey J, McWilliams E, et al. 'Just kids playing sport (in a chair)': Experiences of children, families and stakeholders attending a wheelchair sports club. Disabil Soc 2014;29:938-52.

56. Faigenbaum AD, Kraemer WJ, Blimkie CJ, et al. Youth resistance training: updated position statement paper from the National 
Strength and Conditioning Association. $J$ Strength Cond Res 2009;23:S60-79.

57. Bray N, Noyes J, Edwards RT, et al. Wheelchair interventions, services and provision for disabled children: a mixed-method systematic review and conceptual framework. BMC Health Serv Res 2014;14:309.

58. CONsolidated Standards of Reporting Trials (CONSORT). http:// www.consort-statement.org/consort-2010 (accessed Jan 2014).
59. Medical Research Council. A framework for the development and evaluation of RCTs for complex interventions to improve health. 2000. http://www.mrc.ac.uk/Utilities/Documentrecord/index.htm? d=MRC003372 (accessed Dec 2012).

60. Medical Research Council. Developing and evaluating complex interventions: new guidance. 2008. http://www.mrc.ac.uk/

Utilities/Documentrecord/index.htm?d=MRC004871 (accessed Nov 2012). 